\title{
Personalized approach in brain protection by hypothermia: individual changes in non- pathological and ischemia-related glutamate transport in brain nerve terminals
}

Artem Pastukhov', Natalia Krisanova', Vitalii Maksymenko ${ }^{2,3}$ and Tatiana Borisova ${ }^{\text {** }}$

\begin{abstract}
Background: Both deep and profound hypothermia are effectively applied in cardiac surgery of the aortic arch, when the reduction of cerebral circulation facilitates operations, and for the prevention of ischemic stroke consequences. Neurochemical discrimination of the effects of deep and profound hypothermia $\left(27\right.$ and $17{ }^{\circ} \mathrm{C}$, respectively) on non-pathological and pathological ischemia-related mechanisms of presynaptic glutamate transport with its potential contribution to predictive, preventive and personalized medicine (PPPM) was performed.

Methods: Experiments were conducted using nerve terminals isolated from rat cortex (synaptosomes). Glutamate transport in synaptosomes was analyzed using radiolabel L- $\left[{ }^{14} \mathrm{C}\right] \mathrm{g}$ lutamate. Diameter of synaptosomes was assessed by dynamic light scattering.

Results: Synaptosomal transporter-mediated uptake and tonic release of $\mathrm{L}-\left[{ }^{14} \mathrm{C}\right] \mathrm{glutamate}$ (oppositely directed processes, dynamic balance of which determines the physiological extracellular level of the neurotransmitter) decreased in a different range in deep/profound hypothermia. As a result, hypothermia-induced changes in extracellular L- $\left[{ }^{14} \mathrm{C}\right]$ glutamate are not evident (in one half of animals it increased, and in other it decreased). A progressive decrease from deep to profound hypothermia was shown for pathological mechanisms of presynaptic glutamate transport, that is, transporter-mediated L- $\left[{ }^{14} \mathrm{C}\right]$ glutamate release $(*)$ stimulated by depolarization of the plasma membrane and ${ }^{* *}$ during dissipation of the proton gradient of synaptic vesicles by the protonophore FCCP.

(Continued on next page)
\end{abstract}

\footnotetext{
* Correspondence: tborisov@biochem.kiev.ua

${ }^{1}$ The Department of Neurochemistry, Palladin Institute of Biochemistry, NAS

of Ukraine, 9 Leontovicha Str, Kyiv 01601, Ukraine

Full list of author information is available at the end of the article
} 
(Continued from previous page)

Conclusions: Therefore, the direction of hypothermia-induced changes in extracellular glutamate is unpredictable in "healthy" nerve terminals and depends on hypothermia sensitivity of uptake vs. tonic release. In affected nerve terminals (e.g., in brain regions suffering from a reduction of blood circulation during cardiac surgery, and core and penumbra zones of the insult), pathological transporter-mediated glutamate release from nerve terminals decreases with progressive significance from deep to profound hypothermia, thereby underlying its potent neuroprotective action. So, alterations in extracellular glutamate during hypothermia can be unique for each patient. An extent of a decrease in pathological glutamate transporter reversal depends on the size of damaged brain zone in each incident. Therefore, test parameters and clinical criteria of neuromonitoring for the evaluation of individual hypothermia-induced effects should be developed and delivered in practice in PPPM.

Keywords: Glutamate, Uptake and tonic release, Permanent glutamate turnover, Glutamate transporter reversal, Deep and profound hypothermia, Neuromonitoring, Individual hypothermia regime, Brain nerve terminals

\section{Background}

Hypothermia is effectively practiced in cardiac surgery to facilitate operations on the aortic arch with the reduction of cerebral circulation. The optimal degree of hypothermia for circulatory arrest in aortic arch surgery has been intensively debated, and the concept of using hypothermia to diminish the oxygen consumption and metabolic requirements of hypoxic tissues is rather intuitive [1]. The brain represents only $2-3 \%$ of human body weight; nevertheless, it uses $20-25 \%$ of the total consumption of oxygen and glucose [2]. Postoperative neurologic morbidity and mortality stay elevated and concerns over neurocognitive deficits caused by hypothermic neuronal injury have been raised $[1,3]$, despite data of the literature on complete neurocognitive preservation following deep hypothermic circulatory arrest [4]. Multiple studies using animal models that have attempted to clarify the optimal temperature for hypothermic circulatory arrest have generally supported the use of deeper levels of hypothermia; nevertheless, influence of a range of temperatures on the brain functioning needs to be better assessed [1]. In general, the mechanisms of the neuroprotective action of low temperatures during cardio surgery are a topical issue for medical practitioners.

Ischemic stroke leads to brain impairment and still remains one of the main causes of adult's disability in developed countries. In the central core region of the insult, the neuronal cells are dead within minutes, whereas in the penumbral zone, the survival of the cells is probably achievable. Precise monitoring of brain temperature after stroke, traumatic brain injury, and subarachnoid hemorrhage is important because the brain is particularly susceptible and vulnerable to even small variations in the temperature [5-7]. Therapeutic hypothermia has long been known to be a nonspecific and potent neuroprotectant. It was observed in animal models that hypothermia reduced the size of cerebral infarcts by more than a half and this fact was a base for following clinical trials of therapeutic hypothermia in patients with ischemic stroke $[7,8]$. In human stroke, administration of therapeutic hypothermia can improve short-term survival and neurological recovery and result in less extensive damage of the brain as it can be seen on computed tomography scans [9]. Experimental confirmation and clinical experience show that therapeutic hypothermia has a bright prospect for the administration in acute ischemic brain injury, and the profit is greatest when the treatment is started earlier, namely, within several hours of symptom onset. Low body temperature should be maintained for a longer period after stroke to reach long-lasting neuroprotective outcome [9-12]. Although until now, there are no comprehensible standard parameters of therapeutic hypothermia [13]. Further identification of hypothermia-sensitive pathological process can move ahead this perspective approach.

Glutamate is the main excitatory neurotransmitter in the mammalian central nervous system, which provides and underlies major aspects of normal brain functioning [14]. Impaired glutamate homeostasis leads to harmful neurologic consequences and is a characteristic feature of pathogenesis of neurological disorders. The extracellular glutamate levels are kept low between exocytotic events under normal physiological conditions. These levels are maintained by permanent turnover of the neurotransmitter via the plasma membrane with an input of tonic release from nerve terminals [15]. The turnover is presumably achieved by $\mathrm{Na}^{+}$-dependent highaffinity glutamate transporters (EAAT types 1-3), which utilize gradients of $\mathrm{Na}^{+}$and $\mathrm{K}^{+}$across the plasma membrane as a driving force. Neurotransmitters are accumulated and stored in synaptic vesicles, the acidic compartments of nerve terminals, that release their contents by exocytosis upon stimulation. In cerebral hypoxia, ischemia, stroke, and traumatic brain injury, the development of neurotoxicity is provoked by excesses of extracellular glutamate in the synaptic cleft released through glutamate transporter reversal [16]. 
Temperature influences the properties of the neuronal membrane, postpotential synaptic responses, and release of neurotransmitters (assessed by measuring excitatory postsynaptic potential), and these temperaturedependent changes in electrophysiological properties can result from effects on ion channels of the nerve cells. In fact, some calcium and voltage-gated sodium channels are regulated by temperature $[7,17-20]$. Using microdialysis, Berger [10] demonstrated that moderate hypothermia $\left(33^{\circ} \mathrm{C}\right)$ decreased the concentration of ambient glutamate, pyruvate, lactate, and glycerol in the "tissue at risk" area of the infarct but not within the infarct core. Low body temperature appears to be associated with less release of glutamate in humans that is a marker of ischemia-induced damage of the brain [9].

Many questions are still needed to be answered regarding the use of therapeutic hypothermia, the most important of which is justification of optimal temperature regime. The aim of this study was the discrimination of the effects of hypothermia on nonpathological and pathological mechanisms of presynaptic glutamate transport using rat brain nerve terminals (synaptosomes) and assessment of potential contribution of these results to predictive, preventive and personalized medicine (PPPM). In the study: (*) we analyzed comparatively the dynamics of permanent glutamate turnover between the episodes of exocytosis measuring tonic release, uptake, and the extracellular level of glutamate under conditions of deep and profound hypothermia, and so identified hypothermia-induced changes in ischemiaunaffected nerve terminals, and $(* *)$ we assessed the velocity of pathological glutamate transporter reversal induced by membrane depolarization and the application of the protonophore carbonyl cyanide-p-trifluoromethoxyphenyl-hydrazon (FCCP) under the same conditions. The latest approach allowed identifying hypothermia-induced changes in ischemia-injured nerve terminals.

\section{Methods}

\section{Ethics declaration}

Wistar rats, males, body weight of 100-120 g, were kept in the institute in a quiet, temperature-controlled room at $22-23{ }^{\circ} \mathrm{C}$ using special facilities for animals, where they were provided ad libitum with water and dry food pellets. The experimental procedures were conducted according to the Helsinki Declaration "scientific requirements and research protocols" and "research ethics committees." Experimental protocols were approved by the Animal Care and Use Committee of the Institute (protocol from 19/09-2011). Animals were sacrificed by rapid decapitation [21]. The total number of animals used in this study was 56, i.e., the assessment of L$\left[{ }^{14} \mathrm{C}\right]$ glutamate uptake - 10 animals; release - 16 animals; the extracellular level - 30 animals (different parameters were measured simultaneously using one synaptosome preparation in several experiments). All experiments with rats were performed in accordance to the ARRIVE guidelines for reporting experiments involving animals [22, 23].

\section{Isolation of nerve terminals (synaptosomes) from rat brain}

Cerebral hemispheres were quickly isolated and homogenized in ice-cold solution containing sucrose $(0.32 \mathrm{M})$, HEPES- $\mathrm{NaOH}, \mathrm{pH} 7.4(5 \mathrm{mM})$, and EDTA (0.2 mM). One animal was used to obtain one synaptosome preparation. All procedures were performed at $+4{ }^{\circ} \mathrm{C}$. The synaptosome preparations were obtained by differential centrifugation of rat brain homogenate and then Ficoll400 density gradient centrifugation in accordance to Cotman [24] with minor modifications [25-27]. The experiments using synaptosome preparations can be carried out during $2-4 \mathrm{~h}$ after isolation. The standard salt solution consisted of the following (in $\mathrm{mM}$ ): $\mathrm{NaCl}$ (126); $\mathrm{KCl}$ (5); $\mathrm{MgCl}_{2}$ (2.0); $\mathrm{NaH}_{2} \mathrm{PO}_{4}$ (1.0); HEPES, pH 7.4 (20); D-glucose (10); the solution was oxygenated in all experiments. $\mathrm{Ca}^{2+}$-containing media was supplemented with $\mathrm{CaCl}_{2}(2 \mathrm{mM})$, whereas $\mathrm{Ca}^{2+}$-free media did not contain $\mathrm{Ca}^{2+}$ but was supplemented with EGTA (1 mM). Concentration of proteins was determined in accordance to Larson [28].

\section{Treatment of nerve terminals with hypothermia}

The synaptosomal suspension obtained as described in the previous subsection was used for hypothermia experiments. Hypothermia is classified according to [29] (where deep hypothermia is considered to be from $20^{\circ} \mathrm{C}$ up to $28{ }^{\circ} \mathrm{C}$ and profound from $5{ }^{\circ} \mathrm{C}$ up to $20^{\circ} \mathrm{C}$ ). The measurements were performed both by warming of cold synaptosomal suspension from $4{ }^{\circ} \mathrm{C}$ up to 17,27 , and $37^{\circ} \mathrm{C}$ and vice versa by cooling of preliminary warmed synaptosomal suspension from $37{ }^{\circ} \mathrm{C}$ to 27 and $17{ }^{\circ} \mathrm{C}$ (see below uptake and release experiments).

\section{Dynamic light scattering approach}

Analysis of the size of synaptosomes under hypothermia conditions was performed by dynamic light scattering using a laser correlation spectrometer "ZetaSizer-3" from Malvern Instrument, UK, equipped with $\mathrm{He}-\mathrm{Ne}$ laser LGN-111, $P=25 \mathrm{~mW}, \lambda=633 \mathrm{~nm}$, at scattering angle $90^{\circ}$, and with multi-computing correlator type 7032 ce synaptosome preparations, sample volume of $1 \mathrm{ml}$, were placed in a thermostated cylindrical quartz cuvette, in which diameter is $10 \mathrm{~mm}$. Synaptosome suspensions were repetitively measured for $120 \mathrm{~s}$. Processing of experimental results were performed using computer software service PCS-Size mode v1.61. 
Recording of $\mathrm{L}-\left[{ }^{14} \mathrm{C}\right]$ glutamate uptake by nerve terminals Uptake of $\mathrm{L}-\left[{ }^{14} \mathrm{C}\right]$ glutamate by synaptosome preparations was measured as follows. Synaptosomes (sample volume of $125 \mu \mathrm{l} ; 0.4 \mathrm{mg}$ of protein per milliliter) were preincubated in the standard salt solution at $37{ }^{\circ} \mathrm{C}$ for 8 min (typical experimental approach to restore ionic gradients). Then, the suspensions were cooled to 27 and $17{ }^{\circ} \mathrm{C}$ to reach hypothermia conditions. Also, series of the experiments were performed without abovementioned preliminary incubation of synaptosomes at $37^{\circ} \mathrm{C}$. In these experiments, cold synaptosomes were warmed up to 17,27 , and $37{ }^{\circ} \mathrm{C}$. In both approaches, uptake was started by the application of the mixture of L-glutamate $(10 \mu \mathrm{M})$ supplemented with L- $\left[{ }^{14} \mathrm{C}\right]$ glutamate $(420 \mathrm{nM}$, $0.1 \mu \mathrm{Ci} / \mathrm{ml}$ ), synaptosome preparations were incubated during $1 \mathrm{~min}$, and then quickly sedimented at 10,000 $g$ for $20 \mathrm{~s}$ using a microcentrifuge. $\mathrm{L}-\left[{ }^{14} \mathrm{C}\right]$ glutamate uptake by synaptosomes was calculated as a lowering of radioactivity in aliquots of the supernatant (sample volume of $100 \mu \mathrm{l}$ ) and a radioactivity augmentation in the SDS-treated pellets. Amount of radioactivity was detected using ACS scintillation cocktail (volume per sample of $1.5 \mathrm{ml}$ ) and liquid scintillation counting $[21,30,31]$. Data were collected from several independent experiments performed in triplicate with different synaptosome preparations (n). Data were presented as mean \pm SEM.

\section{Recording of $\mathrm{L}-\left[{ }^{14} \mathrm{C}\right]$ glutamate release from nerve terminals}

Synaptosome preparations were diluted to $2 \mathrm{mg}$ of protein per milliliter and after $10 \mathrm{~min}$ preincubation at $37^{\circ}$ $\mathrm{C}$ were loaded with radiolabeled $\mathrm{L}-\left[{ }^{14} \mathrm{C}\right]$ glutamate, $1 \mathrm{nmol} / \mathrm{mg}$ of protein, and $238 \mathrm{mCi} / \mathrm{mmol}$ in $\mathrm{Ca}^{2+}$-containing media at $37{ }^{\circ} \mathrm{C}$ during $10 \mathrm{~min}$. Then, the synaptosomes were washed with 10 volumes of ice-cold standard salt solution; the pellets were collected and resuspended (final protein concentration of $1 \mathrm{mg} / \mathrm{ml}$ ). The synaptosome preparations (sample volume of $125 \mu \mathrm{l}$, $0.5 \mathrm{mg}$ of protein $/ \mathrm{ml}$ ) were pre-incubated at $37{ }^{\circ} \mathrm{C}$ for $8 \mathrm{~min}$ (typical experimental procedure for restoration of ionic gradients). After that, the synaptosome preparations were cooled to 27 and $17{ }^{\circ} \mathrm{C}$ to reach hypothermia conditions. Also, series of experiments were performed without abovementioned preliminary incubation at $37^{\circ}$ C. In these experiments, cold synaptosomes were warmed up to 17,27 , and $37{ }^{\circ} \mathrm{C}$. Experiments on release of $\mathrm{L}-\left[{ }^{14} \mathrm{C}\right]$ glutamate were carried out in $\mathrm{Ca}^{2+}$-free incubation media, where synaptosomes were incubated for different time intervals $0-30 \mathrm{~min}$ and then rapidly sedimented at $10,000 \times g$ for $20 \mathrm{~s}$ in a microcentrifuge. Release was recorded in $100 \mu \mathrm{l}$ of aliquots of the supernatant and the SDS-treated pellets using scintillation cocktail ACS (volume per sample of $1.5 \mathrm{ml}$ ) and liquid scintillation counting. Total $\mathrm{L}-\left[{ }^{14} \mathrm{C}\right]$ glutamate amount in the synaptosomes was $200,000 \pm 15,000 \mathrm{cpm} /$ $\mathrm{mg}$ protein. For the assessment of tonic release of the neurotransmitter, the synaptosomes were incubated without stimulating agents. DL-TBOA and FCCP were added to synaptosomes at 0 -time point.

\section{Statistical analysis}

Results were presented as mean \pm SEM of $n$ independent experiments. Statistical differences were confirmed by two-tailed Student's $t$ test. Difference was considered significant, when $P \leq 0.05$.

\section{Materials}

HEPES, EGTA, EDTA, DL-TBOA, FCCP, Ficoll 400, and analytical grade salts were purchased from Sigma (USA); ACS-from Amersham (UK); radiolabelled L- $\left[{ }^{14} \mathrm{C}\right]$ glutamate-from Amersham (UK) and PerkinElmer (USA).

\section{Results \\ Rationale}

The majority of the experimental methods usually applied for the analysis of key characteristics of glutamatergic neurotransmission cannot be used in hypothermiarelated studies because they are temperature-sensitive per se. For example, measurements of the membrane potential and synaptic vesicle acidification [32] using potential- and $\mathrm{pH}$-sensitive dyes, respectively, depend not only on temperature-dependent changes in above characteristics but also on the ability of the dye to penetrate the hypothermia-affected plasma membrane etc. Therefore, such experimental data can be incorrect or need additional severe controls. The methodological approach, which allows to measure directly and adequately temperature-dependent changes in presynaptic neurotransmitter transport, involves the use of radiolabelled neurotransmitters.

The experiments on the analysis of hypothermiainduced effects were subdivided in two groups. The first one related to non-pathological processes in normal nerve terminals, that is, assessment of the uptake, tonic release, and the extracellular level of glutamate without and in the presence of glutamate transporter inhibitor DL-threo- $\beta$-benzyloxyaspartate (DL-TBOA) [33]. The second one was associated with pathological ischemiarelated transporter-mediated glutamate release induced by depolarization of the plasma membrane of nerve terminals and dissipation of the proton gradient of synaptic vesicles. This mechanism significantly contributes to the development of excitotoxicity under hypoxia/ischemia conditions.

The experiments were conducted in the suspension of nerve terminals (synaptosomes) isolated from rat brain cerebral hemispheres. They retain major characteristics 
of intact nerve terminals: $(*)$ the ability to maintain the membrane potential and the proton gradient of synaptic vesicles, (**) accomplish uptake and transportermediated release of glutamate, $(* * *)$ exocytosis, etc. Synaptosomes are considered as one of the best systems to study presynaptic processes [34].

\section{Analysis of the size of nerve terminals by dynamic light scattering under conditions of deep and profound hypothermia}

The average diameter of the particles in the synaptosome preparations was evaluated using dynamic light scattering in order to assess whether or not deep/profound hypothermia caused changes in the size of synaptosomes or their aggregation. As shown in Fig. 1, the size of synaptosomes (protein concentration of $0.5 \mathrm{mg}$ / $\mathrm{ml}$ ) was equal to $2.3 \pm 0.3 \mu \mathrm{m}$ in control at $37^{\circ} \mathrm{C}, 2.4 \pm$ $0.1 \mu \mathrm{m}$ at $27{ }^{\circ} \mathrm{C}$, and $2.3 \pm 0.3 \mu \mathrm{m}$ at $17{ }^{\circ} \mathrm{C}$. Therefore, significant changes were not found in the size of synaptosomes at 27 and $17{ }^{\circ} \mathrm{C}$ in comparison with $37^{\circ} \mathrm{C}$, and so exposure of synaptosomes to above temperature conditions did not cause their aggregation at the concentrations used.

\section{Discrimination of hypothermia-induced changes in non- pathological mechanisms of glutamate transport in brain nerve terminals \\ Tonic release of glutamate from nerve terminals under conditions of deep and profound hypothermia}

Definite level of extracellular glutamate is very important for correct synaptic transmission, and appears to be unique individual characteristic of each synapse [35]. It is clear that temperature-induced changes in the extracellular level of $\mathrm{L}-\left[{ }^{14} \mathrm{C}\right]$ glutamate depend on a dynamic balance of oppositely directed processes, that is, uptake and release (see "Background" and "Discussion" sections). In the first set of the experiments, tonic glutamate release from nerve terminals, i.e. one of the abovementioned constituents determined the extracellular level of glutamate, was assessed. Analysis of tonic release of $\mathrm{L}-\left[{ }^{14} \mathrm{C}\right]$ glutamate from synaptosomes revealed that it decreased in conjunction with a reduction of temperature and consisted of $3.9 \pm 0.3 \%$ of total synaptosomal label at $37^{\circ} \mathrm{C}, 0.1 \pm 0.08 \%$ of total synaptosomal label at $27{ }^{\circ} \mathrm{C}(P \leq 0.001$, Student's $t$ test, $n=20)$, and $0.74 \pm 0.08 \%$ of total synaptosomal label at $17{ }^{\circ} \mathrm{C}(P \leq$ 0.001 , Student's $t$ test, $n=20$ ). Tonic release of $\mathrm{L}-$ $\left[{ }^{14} \mathrm{C}\right]$ glutamate from synaptosome preparations was calculated for $6 \mathrm{~min}$, i.e., between 8- and 14-min time points, starting from warming of synaptosomes from +4 to 17,27 , and $37^{\circ} \mathrm{C}$, and vice versa by cooling from 37 to 27 and $17{ }^{\circ} \mathrm{C}$. Therefore, tonic release of $\mathrm{L}-\left[{ }^{14} \mathrm{C}\right] \mathrm{glu}-$ tamate significantly decreased under conditions of hypothermia, and unexpectedly, this decrease was more

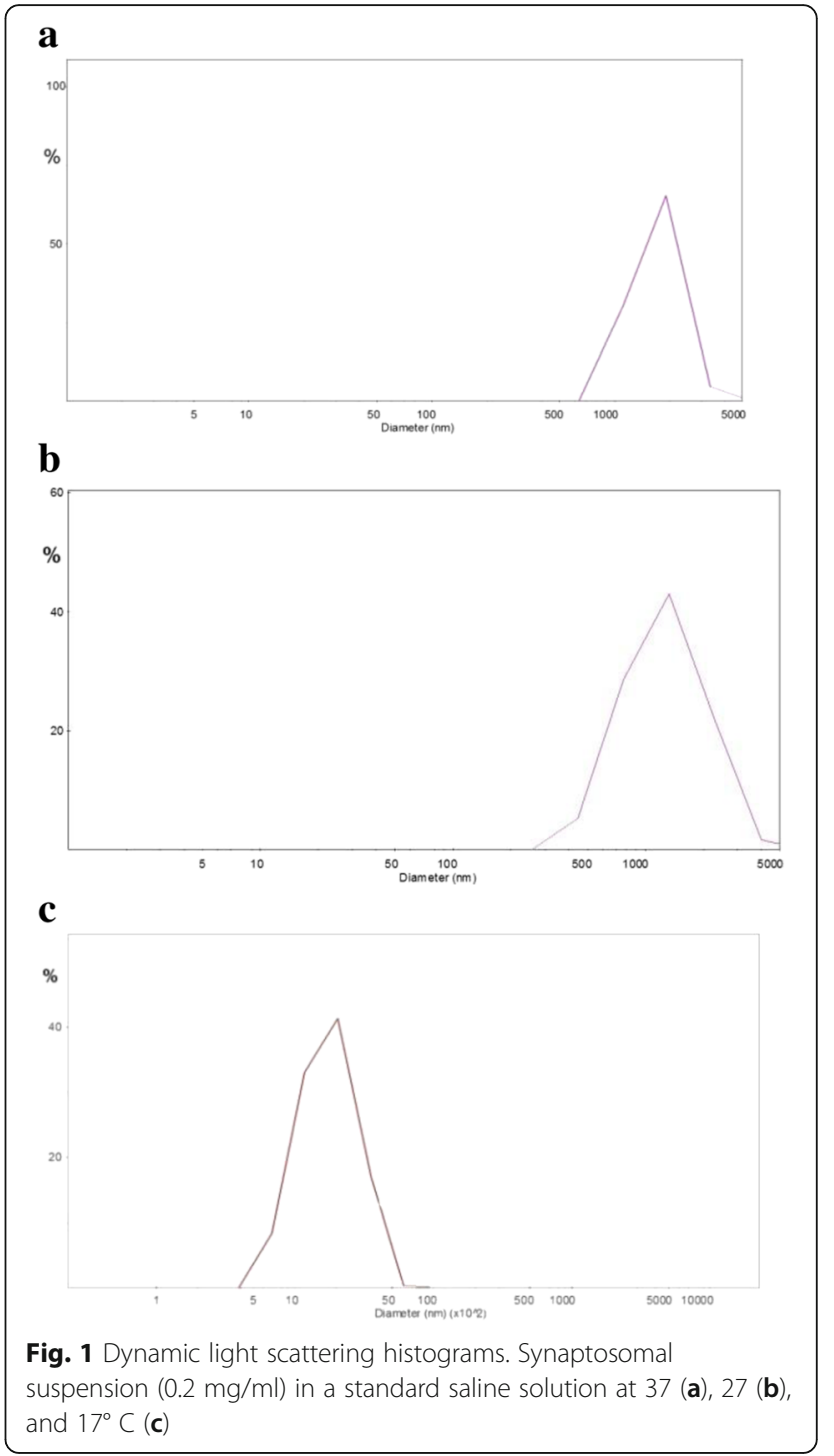

considerable in deep than in profound hypothermia (Fig. 2).

Transporter-mediated glutamate uptake by nerve terminals under conditions of deep and profound hypothermia

As shown in Fig. 3, deep and profound hypothermia caused significant changes in the initial velocity of L$\left[{ }^{14} \mathrm{C}\right]$ glutamate uptake by synaptosomes. The initial velocity of $\mathrm{L}-\left[{ }^{14} \mathrm{C}\right]$ glutamate uptake by synaptosomes was equal to $2.63 \pm 0.08 \mathrm{nmol} \mathrm{min}{ }^{-1} \mathrm{mg}^{-1}$ protein at $37^{\circ} \mathrm{C}$, decreased to $2.09 \pm 0.2 \mathrm{nmol} \mathrm{min}{ }^{-1} \mathrm{mg}^{-1}$ protein at $27^{\circ}$ $\mathrm{C}$, and further decreased to $1.48 \pm 0.12 \mathrm{nmol} \mathrm{min}{ }^{-1} \mathrm{mg}$ ${ }^{-1}$ protein at $17{ }^{\circ} \mathrm{C}(P \leq 0.05$, Student's $t$ test, $n=6)$. Accumulation of $\mathrm{L}-\left[{ }^{14} \mathrm{C}\right]$ glutamate by synaptosomes for $10 \mathrm{~min}$ consisted of $9.83 \pm 0.35 \mathrm{nmol} \mathrm{mg}{ }^{-1}$ protein at $37{ }^{\circ} \mathrm{C}, 7.42 \pm 0.27 \mathrm{nmol} \mathrm{min}{ }^{-1}$ protein at $27^{\circ} \mathrm{C}$, and 5.75 $\pm 0.52 \mathrm{nmol} \mathrm{mg}{ }^{-1}$ protein at $17{ }^{\circ} \mathrm{C}(P \leq 0.05$, Student's $t$ test, $n=6)$. Therefore, deep and profound hypothermia 


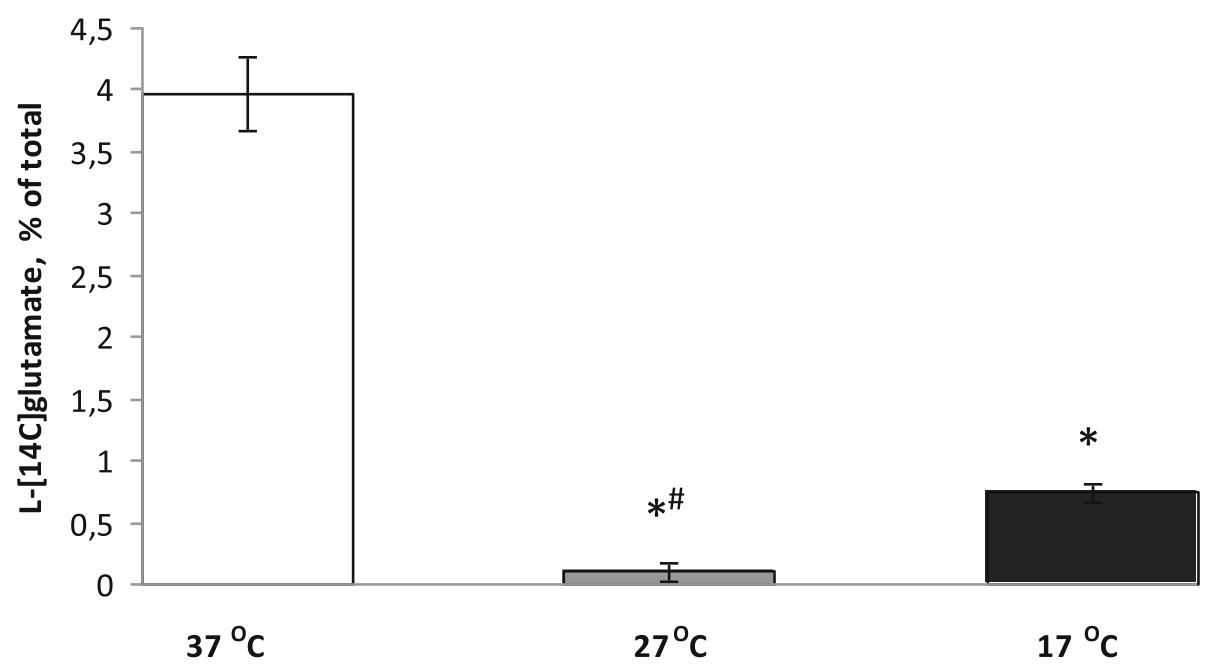

Fig. 2 Tonic release of $L-\left[{ }^{14} \mathrm{C}\right]$ glutamate from nerve terminals under conditions of deep and profound hypothermia. 37 (empty column), at 27 (grey column), and $17{ }^{\circ} \mathrm{C}$ (black column). L-[ $\left.{ }^{[4} \mathrm{C}\right]$ glutamate release was measured as described in the "Methods" section. Total synaptosomal L- $\left[{ }^{14} \mathrm{C}\right] \mathrm{glutamate}$ content was equal to $200,000 \pm 15,000 \mathrm{cpm} / \mathrm{mg}$ protein. Data are means \pm SEM of 30 independent experiments, each performed in triplicate. Data are compared by Student's $t$ test. *, $P \leq 0.001$ as compared to synaptosomes at $37^{\circ} \mathrm{C}$; , as compared to synaptosomes at $17^{\circ} \mathrm{C}$

significantly inhibited $\quad \mathrm{L}-\left[{ }^{14} \mathrm{C}\right]$ glutamate uptake by synaptosomes.

\section{The extracellular level of glutamate in the preparations of nerve terminals under conditions of deep and profound hypothermia}

As it was indicated in the previous sections, definite extracellular glutamate concentration in nerve terminals is maintained by oppositely directed processes, that is, uptake and release. The extracellular level of $\mathrm{L}-\left[{ }^{14} \mathrm{C}\right]$ glutamate in the synaptosome preparations was measured at 14-min time point after warming or cooling of synaptosomes (see "Methods" section). To obtain representative experimental data, more than 30 experiments with synaptosomal preparations isolated from different animals were performed that were an order more than for usual measurements per parameter (Fig. 4). It was calculated that in a half of the experiments extracellular $\mathrm{L}-\left[{ }^{14} \mathrm{C}\right]$ glutamate was decreased in hypothermia (Fig. 5a), and in a half-it was increased (Fig. 5b). Statistical analysis of the experimental data from both groups revealed the absence of significance between the control and hypothermia. This fact can be explained by

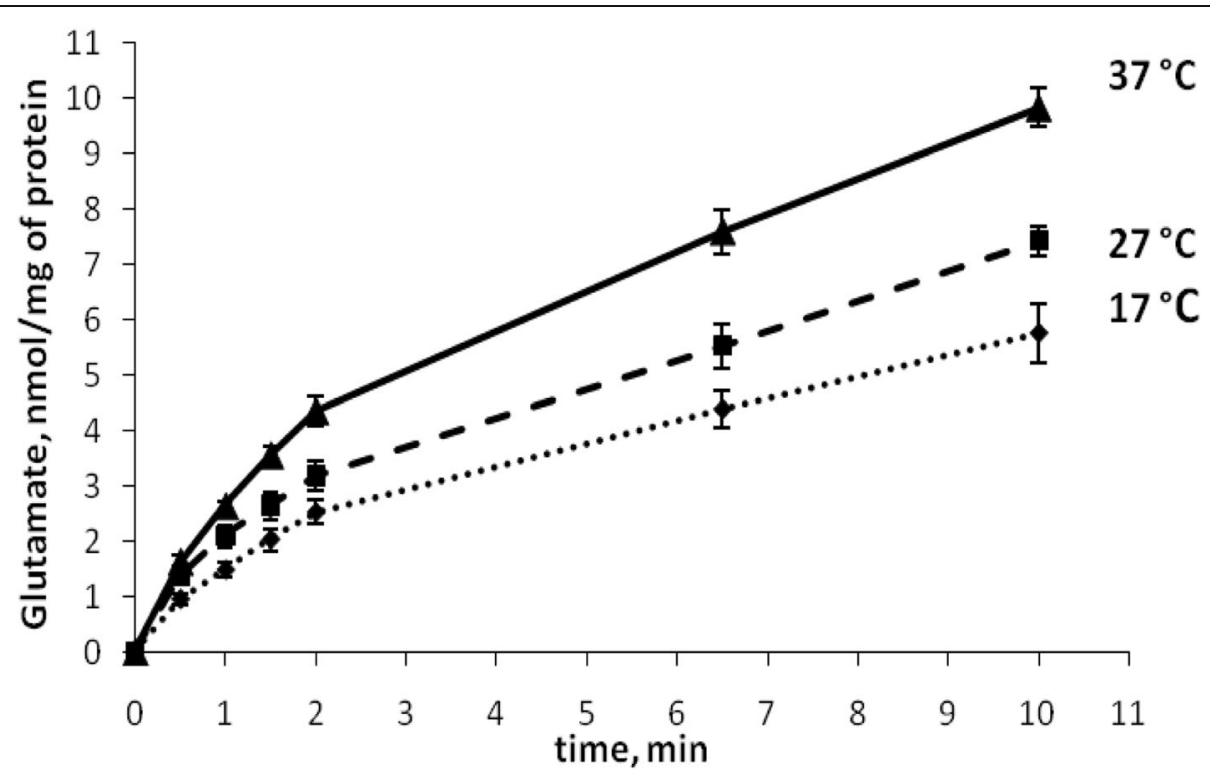

Fig. 3 Time course of L-[ $\left[{ }^{14} \mathrm{C}\right]$ glutamate uptake by nerve terminals under conditions of deep and profound hypothermia. 37 (solid line), 27 (dash line), and $17^{\circ} \mathrm{C}$ (dotted line). L- $\left[{ }^{14} \mathrm{C}\right]$ glutamate uptake was measured as described in the "Methods" section 
the uniqueness of release/uptake balance established in each synapse, which is determined by individual synaptic characteristics such as the amount and distribution of glutamate transporters, lipid composition of the plasma membrane, and energetical status of nerve terminals. As a result, in one animal, a decrease in uptake prevails on a decrease in tonic release of $\mathrm{L}-\left[{ }^{14} \mathrm{C}\right]$ glutamate and in other one vice versa. As shown in Fig. 4, the average extracellular level of $\mathrm{L}-\left[{ }^{14} \mathrm{C}\right]$ glutamate was changed insignificantly as a result of a decrease in the temperature. At 14-min time point after warming/cooling of cold/warm synaptosomes, it consisted of $280 \pm 28 \mathrm{pmol} / \mathrm{mg}$ of protein at $37^{\circ} \mathrm{C}, 212 \pm 23 \mathrm{pmol} / \mathrm{mg}$ of protein at $27^{\circ} \mathrm{C}$, and $241 \pm 23 \mathrm{pmol} / \mathrm{mg}$ of protein at $17{ }^{\circ} \mathrm{C}(n=30)$ (Fig. 4). Therefore, it was concluded that in comparison to significantly inhibited uptake and tonic release of $\mathrm{L}-\left[{ }^{14} \mathrm{C}\right]$ glutamate, the extracellular $\mathrm{L}-\left[{ }^{14} \mathrm{C}\right]$ glutamate level was changed insignificantly under deep/profound hypothermia. The only explanation of this fact is that tonic release decreased with comparable effectiveness with L$\left[{ }^{14} \mathrm{C}\right]$ glutamate uptake, and so lowering of $\mathrm{L}-\left[{ }^{14} \mathrm{C}\right]$ glutamate leakage competed with weakness of uptake.

The next set of the experiments was performed for assessment of hypothermia-induced changes in the value of the extracellular level of $\mathrm{L}-\left[{ }^{14} \mathrm{C}\right]$ glutamate in the suspension of nerve terminals during blockage of glutamate transporter functioning by competitive non-transportable inhibitor of glutamate transporters DL-threo- $\beta$-benzyloxyaspartate (DL-TBOA) [33]. The extracellular level of L- $\left[{ }^{14} \mathrm{C}\right]$ glutamate in synaptosome preparations significantly decreased in deep/profound hypothermia under conditions of inhibition of glutamate uptake. No significant difference in extracellular $\mathrm{L}-\left[{ }^{14} \mathrm{C}\right]$ glutamate in synaptosome preparations in the presence of glutamate transporter blocker was revealed between deep and profound hypothermia.
Discrimination of hypothermia-induced changes in pathological ischemia-related mechanisms of glutamate transport in brain nerve terminals

Stimulated by depolarization of the plasma membrane transporter-mediated release of glutamate from nerve terminals under conditions of deep and profound hypothermia In hypoxia, ischemia, stroke, brain trauma, hypoglycemia, etc, an increase in the extracellular glutamate level causes neurotoxicity and neuronal death. Transporter-mediated glutamate release is the main mechanism that leads to an augmentation of the extracellular glutamate concentration under these pathological conditions. Depolarization of the plasma membrane of nerve terminals by high $\mathrm{KCl}$ in $\mathrm{Ca}^{2}$ ${ }^{+}$-free medium causes reversal of glutamate transporters and transporter-mediated release of glutamate from the cytosol. It was shown that stimulation by high $\mathrm{KCl}$ release of $\mathrm{L}-\left[{ }^{14} \mathrm{C}\right]$ glutamate decreased in a progressive way under conditions of deep and profound hypothermia. The value of this release measured at 6 -min time point was equal to $12 \pm 1 \%$ of total accumulated label at $37{ }^{\circ} \mathrm{C}, 10.0 \pm 0.5 \%$ of total accumulated label at $27{ }^{\circ} \mathrm{C}$, and $6.0 \pm 0.5 \%$ of total accumulated label at $17{ }^{\circ} \mathrm{C}(P \leq 0.05$, Student's $t$ test, $n=5)$ (Fig. 6). Therefore, data on depolarization-evoked transporter-mediated release of $\mathrm{L}_{-}\left[{ }^{14} \mathrm{C}\right]$ glutamate from synaptosomes showed that the velocity of this release was decreased gradually from deep to profound hypothermia.

\section{Protonophore-induced glutamate release from nerve terminals under conditions of deep and profound hypothermia}

The protonophore FCCP is used in the experiments due to its ability to dissipate the proton gradient of synaptic vesicles and inhibit glutamate uptake [27]. These conditions favor an augmentation of transporter-mediated L-

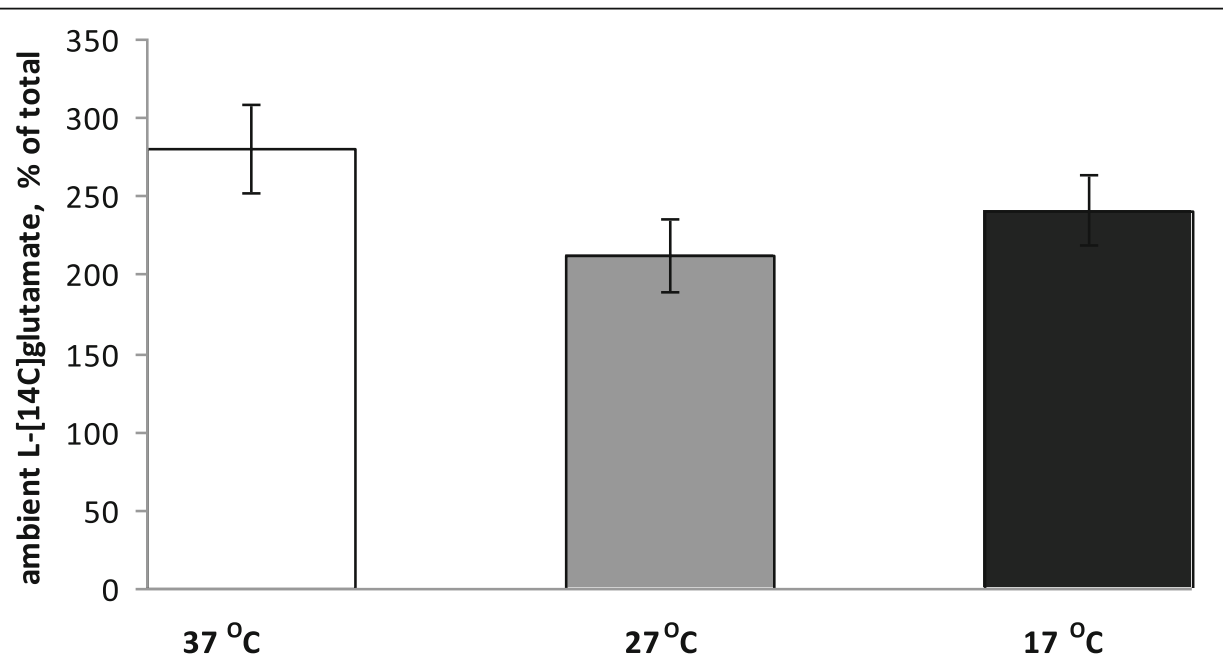

Fig. 4 The extracellular level of $\mathrm{L}-\left[{ }^{14} \mathrm{C}\right]$ glutamate in the synaptosomal suspension under conditions of deep and profound hypothermia. The level was measured at 14-min time point (see the "Methods" section) at 37 (empty column), 27 (grey column), and $17^{\circ} \mathrm{C}$ (black column). Total synaptosomal L- $\left.{ }^{14} \mathrm{C}\right] \mathrm{glu}$ tamate content was equal to $200,000 \pm 15,000 \mathrm{cpm} / \mathrm{mg}$ protein. Data are means \pm SEM of 30 independent experiments, each performed in triplicate 


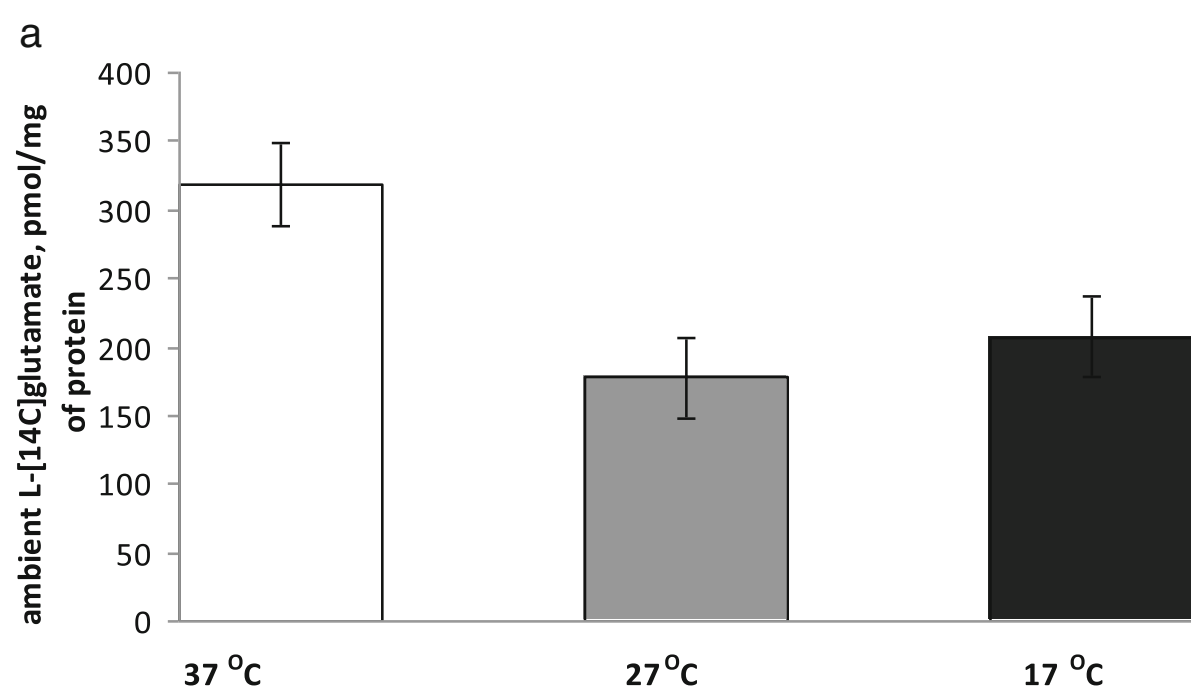

b

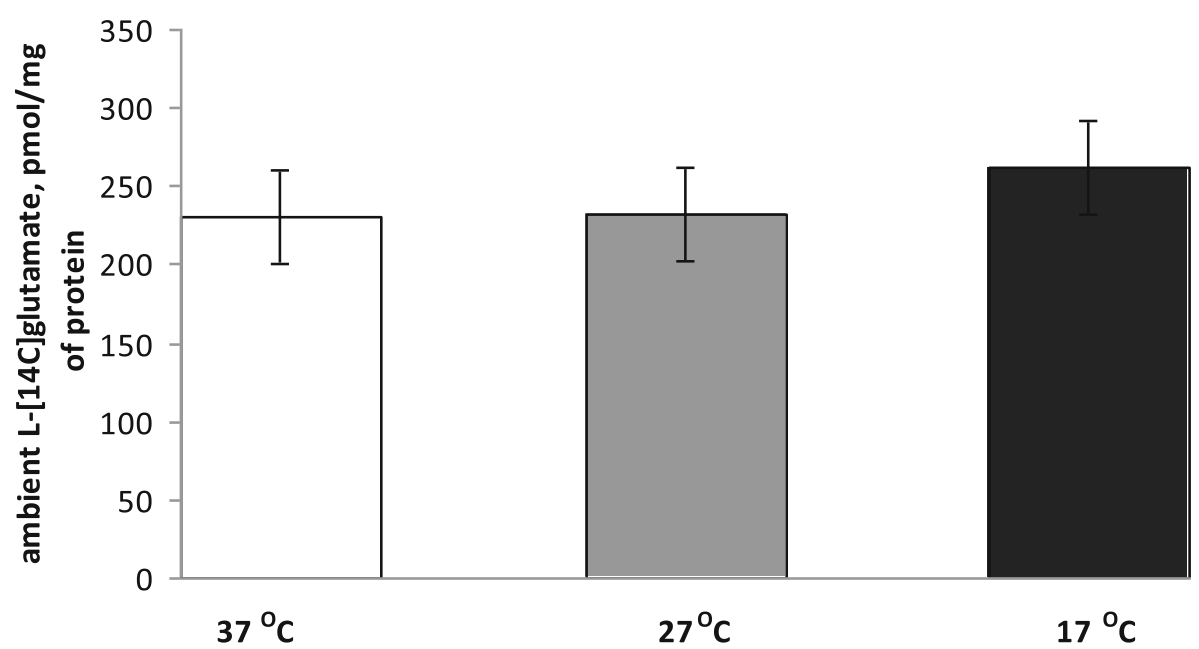

Fig. $\mathbf{5}$ Two groups of animals with different changes in the extracellular level of $\mathrm{L}-\left[{ }^{14} \mathrm{C}\right]$ glutamate in the synaptosomal suspension under conditions of deep and profound hypothermia. The experiments were subdivided in two groups with a tendency to decrease (a) and increase (b) in the value of extracellular $\mathrm{L}-\left[{ }^{14} \mathrm{C}\right]$ glutamate in the synaptosomal suspension in hypothermia. The level was measured at 14-min time point (see the "Methods" section) at 37 (empty columns), 27 (grey columns), and $17{ }^{\circ} \mathrm{C}$ (black columns). Total synaptosomal L- $\left[{ }^{14} \mathrm{C}\right]$ glutamate content was equal to $200,000 \pm 15,000 \mathrm{cpm} / \mathrm{mg}$ protein. Data are means \pm SEM of 30 independent experiments, each performed in triplicate

$\left[{ }^{14} \mathrm{C}\right]$ glutamate release from synaptosomes. FCCPevoked $\mathrm{L}-\left[{ }^{14} \mathrm{C}\right]$ glutamate release from synaptosomes was significantly inhibited by the transporter inhibitor DLTBOA, so this release was mediated by glutamate transporters. In this set of the experiments, the effect of deep and profound hypothermia on $\mathrm{L}_{-}\left[{ }^{14} \mathrm{C}\right]$ glutamate release from synaptosomes during application of FCCP was analyzed. As shown in Fig. 7, FCCP-evoked release of L$\left[{ }^{14} \mathrm{C}\right]$ glutamate for $6 \mathrm{~min}$ was equal to $15.5 \pm 1.0 \%$ of total accumulated label at $37{ }^{\circ} \mathrm{C}, 9.5 \pm 1.0 \%$ of total accumulated label at $27{ }^{\circ} \mathrm{C}(P \leq 0.05$, Student's $t$ test, $n=4)$, and $6.3 \pm$ $0.5 \%$ of total accumulated label at $17{ }^{\circ} \mathrm{C}(P \leq 0.05$, Student's $t$ test, $n=4)$.

\section{Discussion}

Glutamate-related mechanism of neuroprotective action of hypothermia is still debated despite a lot of experimental data $[7,10,18,19,36]$. The explanation of the possible neuroprotective effect of lowering body temperature in acute stroke remains largely speculative [9]. However, most studies point toward lowering down of the neurodegenerative processes in the penumbra $[18,19,37,38]$. Also, there are no clear standards of the parameters in therapeutic hypothermia [13], and the optimal temperature for hypothermic circulatory arrest during arch surgery remains unclear [1]. 


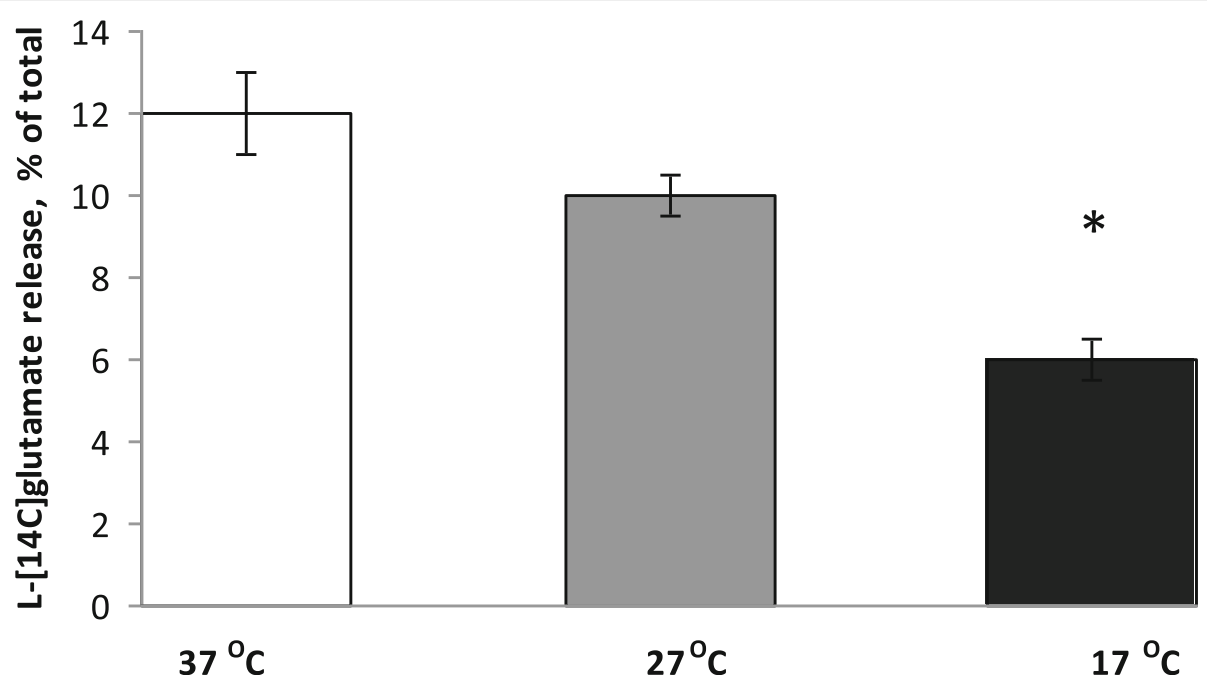

Fig. 6 Stimulated by high $\mathrm{KCl}(35 \mathrm{mM})$ transporter-mediated release of $\mathrm{L}-\left[^{14} \mathrm{C}\right]$ glutamate from nerve terminals under conditions of deep and profound hypothermia. Release was measured at 37 (empty columns), 27 (grey columns), and $17^{\circ} \mathrm{C}$ (black columns). L- $\left[{ }^{14} \mathrm{C}\right]$ glutamate release was measured as described in the "Methods" section, and $\mathrm{L}-\left[{ }^{[4} \mathrm{C}\right]$ glutamate radioactivity was determined at 6-min time point. Data are means \pm SEM of five independent experiments, each performed in triplicate. ${ }^{*}, P \leq 0.05$ as compared to the control

In this study, double discrimination of the effects of deep and profound hypothermia (the first type of discrimination) on non-pathological and pathological mechanisms (the second type of discrimination) of presynaptic L- $\left[{ }^{14} \mathrm{C}\right]$ glutamate transport was performed using rat brain nerve terminals. According to the recent hypothesis forwarded by the author of this study, a definite and non-negligible concentration of extracellular glutamate between the episodes of exocytotic release is established mainly by permanent transporter-mediated glutamate turnover across the plasma membrane of nerve terminals with a contribution of non-transporter tonic glutamate release by spontaneous exocytosis, diffusion, cystine-glutamate exchanger, and leakage through anion channels [15]. Nevertheless, glutamate transporter reversal remains the major mechanism of glutamate release under energy deprivation conditions, in hypoxia, hypoglycemia, brain trauma, stroke, underlying augmentation of the extracellular glutamate concentration, and development of excitotoxicity. Dynamics of $\mathrm{L}-\left[{ }^{14} \mathrm{C}\right] \mathrm{glu}-$ tamate turnover (between episodes of exocytosis) and its constitutive mechanisms, that is, high-affinity $\mathrm{Na}$ ${ }^{+}$-dependent uptake accompanied with non-pathological transporter-mediated release of $\mathrm{L}-\left[{ }^{14} \mathrm{C}\right]$ glutamate, and

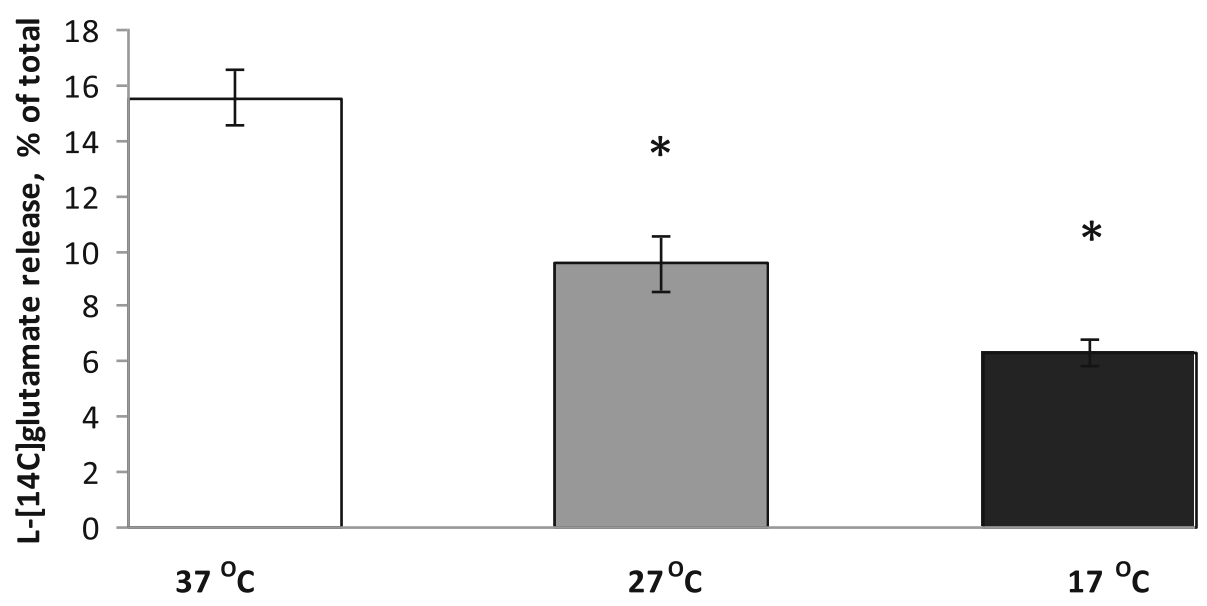

Fig. $\mathbf{7}$ Transporter-mediated release of $\mathrm{L}-\left[{ }^{14} \mathrm{C}\right]$ glutamate from nerve terminals in the presence of the protonophore FCCP $(1 \mu \mathrm{M})$ under conditions of deep and profound hypothermia. L- $\left[{ }^{14} \mathrm{C}\right]$ glutamate release was measured as described in the "Methods" section, and L- $\left[{ }^{14} \mathrm{C}\right]$ glutamate radioactivity was determined at 6-min time point. 37 (empty columns), 27 (grey columns), and $17{ }^{\circ} \mathrm{C}$ (black columns). Data are means \pm SEM of four independent experiments, each performed in triplicate. ${ }^{*}, P \leq 0.05$ as compared to control 
also tonic $\mathrm{L}-\left[{ }^{14} \mathrm{C}\right]$ glutamate release, were analyzed separately under conditions of deep and profound hypothermia. A balance of hyperthermia-induced changes in above constituents determines definite extracellular level of L$\left[{ }^{14} \mathrm{C}\right]$ glutamate in nerve terminals under experimental conditions. It was shown that transporter-mediated L- $\left[{ }^{14} \mathrm{C}\right]$ glutamate uptake was decreased in progressive manner from deep to profound hypothermia (Fig. 3). Theoretical calculations predict that non-pathological glutamate transporter reversal (as a component of permanent transportermediated turnover) should also decrease under hypothermia. Unfortunately, this component cannot be measured directly by any methodological approaches.

Tonic release of $\mathrm{L}-\left[{ }^{14} \mathrm{C}\right]$ glutamate for $6 \mathrm{~min}$ decreased more considerably (almost completely absent) under conditions of deep hypothermia (Fig. 2, the second column) in comparison with profound one (Fig. 2, the third column). It was clearly demonstrated that no gradual decrease in tonic $\mathrm{L}-\left[{ }^{14} \mathrm{C}\right]$ glutamate release between deep and profound hypothermia was registered. Summarizing, uptake of $\mathrm{L}-\left[{ }^{14} \mathrm{C}\right]$ glutamate decreased progressively (Fig. 3), whereas tonic release decreased almost similarly in deep to profound hypothermia by more than $80 \%$ (Fig. 2).

Theoretical calculations predict that if transportermediated L- $\left[{ }^{14} \mathrm{C}\right]$ glutamate uptake is more sensitive to deep and profound hypothermia than the sum of nonpathological transporter-mediated and non-transporter tonic release of $\mathrm{L}-\left[{ }^{14} \mathrm{C}\right]$ glutamate, the extracellular level of $\mathrm{L}-\left[{ }^{14} \mathrm{C}\right]$ glutamate should increase in the preparation of nerve terminals and vice versa if release is more sensitive-this level should decrease. Taking ten times more animals than for ordinary series of the experiments, it was shown that the ability to maintain the balance glutamate $_{\text {in }} /$ glutamate $_{\text {out }}$ in hypothermia, and so extracellular level of $\mathrm{L}-\left[{ }^{14} \mathrm{C}\right]$ glutamate was individual for each animal. It is so because in $50 \%$ of experiments, the extracellular $\mathrm{L}-\left[{ }^{14} \mathrm{C}\right]$ glutamate level was decreased under hypothermia (Fig. 5a) and in 50\%-it was increased (Fig. 5b). As a result, the statistic calculation showed the absence of significance in hypothermia-dependent decrease in the extracellular level of $\mathrm{L}-\left[{ }^{14} \mathrm{C}\right]$ glutamate in the preparation of nerve terminals (Fig. 4).

Absence of significant changes in extracellular L$\left[{ }^{14} \mathrm{C}\right]$ glutamate in the preparation of nerve terminals despite of reduced $\mathrm{L}-\left[{ }^{14} \mathrm{C}\right]$ glutamate uptake during lowering of temperature is valuable per se. It is clear from these hypothermia experiments that release components (tonic and non-pathological transporter reversal) have significant contribution to the establishment and maintenance of proper extracellular glutamate concentration. Variability of hypothermia-induced changes in extracellular L- $\left[{ }^{14} \mathrm{C}\right]$ glutamate shown in this study favors our recent suggestion regarding individuality and uniqueness of the extracellular level of the neurotransmitters for each synapse [35].

Therefore, the effect of therapeutic hypothermia on the extracellular level of glutamate in nerve terminals unaffected by hypoxia/ischemia cannot be predicted a priori. Taking into account the above fact, it is clear that the changes in the extracellular level of glutamate during hypothermia are unique for each patient, and so the individual approach of the evaluation of hypothermia parameters should be developed.

Our data coincides with the results of Boris-Moller and Wieloch [39], who found an attenuation of glutamate levels only in the striatum, whereas cortical ones, although were lower at the baseline, but were not attenuated by hypothermia. However, the experimental data is not in accord with microdialysis measurements that demonstrated that glutamate dialysate concentrations in non-infarcted brain tissue decreased from 3.6 to $2.6 \mathrm{~mol} / \mathrm{L}$ in mild hypothermia [10]. Only a tendency to decrease in synaptosomal extracellular $\mathrm{L}-\left[{ }^{14} \mathrm{C}\right]$ glutamate was found in our experiments.

This study also focused on the analysis of the velocity of pathological glutamate transporter reversal induced by membrane depolarization and FCCP that reflected hypothermia-induced changes in ischemia-injured nerve terminals. Development of neurotoxicity in stroke, cerebral hypoxia, and ischemia, cardio surgery with circulation arrest, and traumatic brain injury is provoked by excessive extracellular glutamate mainly originated from glutamate transporter reversal. Glutamate transporter reversal was stimulated by depolarization of the plasma membrane by $35 \mathrm{mM} \mathrm{KCl} \mathrm{(Fig.} \mathrm{6)} \mathrm{and} \mathrm{by} \mathrm{dissipation} \mathrm{of}$ the proton gradient of synaptic vesicles with the protonophore FCCP (Fig. 7), and a gradual decrease from deep to profound hypothermia in the velocity of transporter-mediated $\mathrm{L}-\left[{ }^{14} \mathrm{C}\right]$ glutamate release from synaptosomes was shown. This fact indicates a progressive neuroprotective effect increased from deep to profound hypothermia in affected by hypoxia/ischemia zones, e.g., in core and penumbra zones of the insult. This experimental data coincides with the results of [40], where the authors analyzing the dialysate concentrations showed that the rate of an ischemia-induced increase in glutamate concentration was inhibited by low temperature, and was equal to $58.4 \pm 31.8 \mu \mathrm{mol} / \mathrm{L}$ at $38{ }^{\circ} \mathrm{C}$ to $15.9 \pm$ $8.4 \mu \mathrm{mol} / \mathrm{L}$ at $25^{\circ} \mathrm{C}$. Also, our results agree with those of Berger [10], where the authors demonstrated using microdialysis measurements that glutamate dialysate concentrations in peri-infarct tissue were significantly influenced by hypothermia (extracellular glutamate, 4.8 versus $12.6 \mathrm{~mol} / \mathrm{L}$ ). In this context, we partially agree with the suggestion that hypothermia exerts a neuroprotective effect by extracellular glutamate attenuation in penumbral regions and possibly within the infarct core. 
The present study brings new insight to the above statement, namely, it is true, when the nerve cells are still able to release glutamate by transporter reversal (Figs. 6 and 7) and also by non-transporter mechanisms (Fig. 2). In considerably injured nerve cells, the above mechanisms do not work because of thermodynamic reasons, i.e., reduction of the glutamate ${ }_{\text {in }} /$ glutamate $_{\text {out }}$ gradient across the plasma membrane. In this context, selection of optimal individual temperature regime for patients in dependence of the size of irreversibly injured zone and extent of penumbra one is of value.

Taking into account abovementioned facts, it is suggested that the strategy of successful therapeutic hypothermia from one side is a reduction of its possible harmful effects on hypoxia/ischemia-unaffected nerve cells by stabilization of the extracellular glutamate concentration through the balancing release/uptake constituents. It is rational to make hypothermia-induced decrease in glutamate transporter reversal more significant, thereby enhancing its direct neuroprotective effect. Above recommendations can be realized by combination of unspecific effects of hypothermia with other unspecific and specific neuroprotectants.

In medical practice, there are no specific agents for modulation of glutamate transporter activity, in contrast to selective inhibitors of GAT1 and GAT3 GABA transporters, tiagabine, and $\beta$-alanine, respectively. In this context, unspecific modulation of transporter activity is the only available approach to decrease significantly pathological transporter-mediated glutamate release from nerve terminals. Unspecific neuroprotection can be performed by hypothermia and also by temporal cholesterol deficiency. Recently, we have shown that a decrease in the level of membrane cholesterol in nerve terminals reduced pathological transporter-mediated glutamate release. These data can explain the neuroprotective effect followed by the administration of statins in excitotoxicity, stroke, cerebral hypoxia and ischemia, seizures, oxidative damage, and traumatic brain injury. However, we underline that except abovementioned pathologies, the normal levels of membrane cholesterol are extremely important for correct synaptic transmission and a decrease in membrane cholesterol content of nerve terminals may cause neurotoxic consequences because of weak glutamate uptake and the enlargement of the extracellular glutamate concentration [32, 41, 42]. Also, nanoparticles can be perspective for modulation of glutamate transport and visualization of key processes in nerve terminals [43].

\section{Limitations of the study}

The main limitation of this study is associated with the fact that data was obtained from in vitro experiments. Nevertheless, the existence of pathological glutamate transporter reversal and importance of the extracellular glutamate level is commonly accepted $[10,14,16]$.

\section{Recommendations for PPPM}

The results of this study are of value for PPPM, a medicine that focuses on the combined diagnosis, prevention, and treatment of disease in individual patients. Discrimination of hypothermia-induced changes in nonpathological and pathological glutamate transport in nerve terminals, proven diversity of above hypothermiainduced effects, and individuality of changes in extracellular glutamate underscores usefulness of the result implementation in PPPM. It is suggested from our study that the neurological complications in cardiac surgery can be associated with an increase extracellular glutamate level. In "healthy" nerve terminals, hypothermiainduced changes in the extracellular glutamate level cannot be predicted because hypothermia sensitivity of uptake vs. tonic release cannot be assessed by known approaches. However, blood platelets are able to accomplish glutamate uptake by neuronal-like high-affinity $\mathrm{Na}$ ${ }^{+}$-dependent glutamate transporters EAAT 1-3 of the plasma membrane [35]. This feature of platelets may be used for characterization of hypothermia sensitivity of glutamate transport in brain nerve terminals. Similarities of platelets with nerve terminals underlie possible usage of platelets as a model of glutamate transport in the presynapse and an analytic, diagnostic, and prognostic biomarker for the analysis of the alterations in the functioning of glutamate transporters in the brain [35]. Interrelation between changes in glutamate transport and metabolism in the brain and platelets was shown [44-47], and so the possible role of platelets as a diagnostic and prognostic marker in various neurodegenerative diseases was suggested [48]. The probable physiological role of platelets in extracellular glutamate homeostasis in the central nervous system is realized by removing of excessive extracellular glutamate [49-52]. The importance of proper glutamate concentration in the blood was demonstrated in [53].

Taking into account our data on significant gradual decrease in pathological glutamate transporter reversal, it is clear that the more size of penumbra zone, the less temperature in therapeutic hypothermia should be applied. Preliminary diagnostics and neuromonitoring should be an essential part of hypothermia therapy helping physicians to choose optimal temperature regime. Increased plasma glutamate in stroke patients was registered [48]. In this context, non-neuronal glutamate can serve as a diagnostic, prognostic, and predictive biomarker, and glutamate biosensor [31] can be applied in medical practice. In contrast, platelets cannot be included in neuromonitoring of pathological glutamate transporter reversal, because we recently showed that 
this manner of glutamate release in platelets is rather ambiguous [35] and glutamate is released from platelets exclusively by means of exocytosis.

Therefore, the PPPM goal for the future is to implement comprehensive neuromonitoring of glutamaterelated parameters in the blood plasma, platelets, and cerebrospinal liquids that helps to select optimal individual temperature regime for patients with prescribed therapeutic hypothermia (Fig. 8). Validation of proposed biomarkers, i.e., glutamate concentration in the blood and cerebrospinal liquids and glutamate transport characteristics of platelets, is necessary before their incorporation into standard clinical decision-making algorithms.
Personalized approach will certainly play the crucial role in the more effective and better tailored hypothermia treatment in cardiac surgery of the aortic arch and in ischemic stroke.

In perspective, we plan to develop the panels of glutamate-related biomarkers for neuromonitoring of the patients reflected individual hypothermia-induced effects in nerve terminals that will serve for the outcome prediction methodology. This plan bases on our recent results that the extracellular glutamate level is unique for each synapse [35], a possibility to analyze kinetics of glutamate uptake by nerve terminals using glutamate biosensor [31], and characteristic features of glutamate

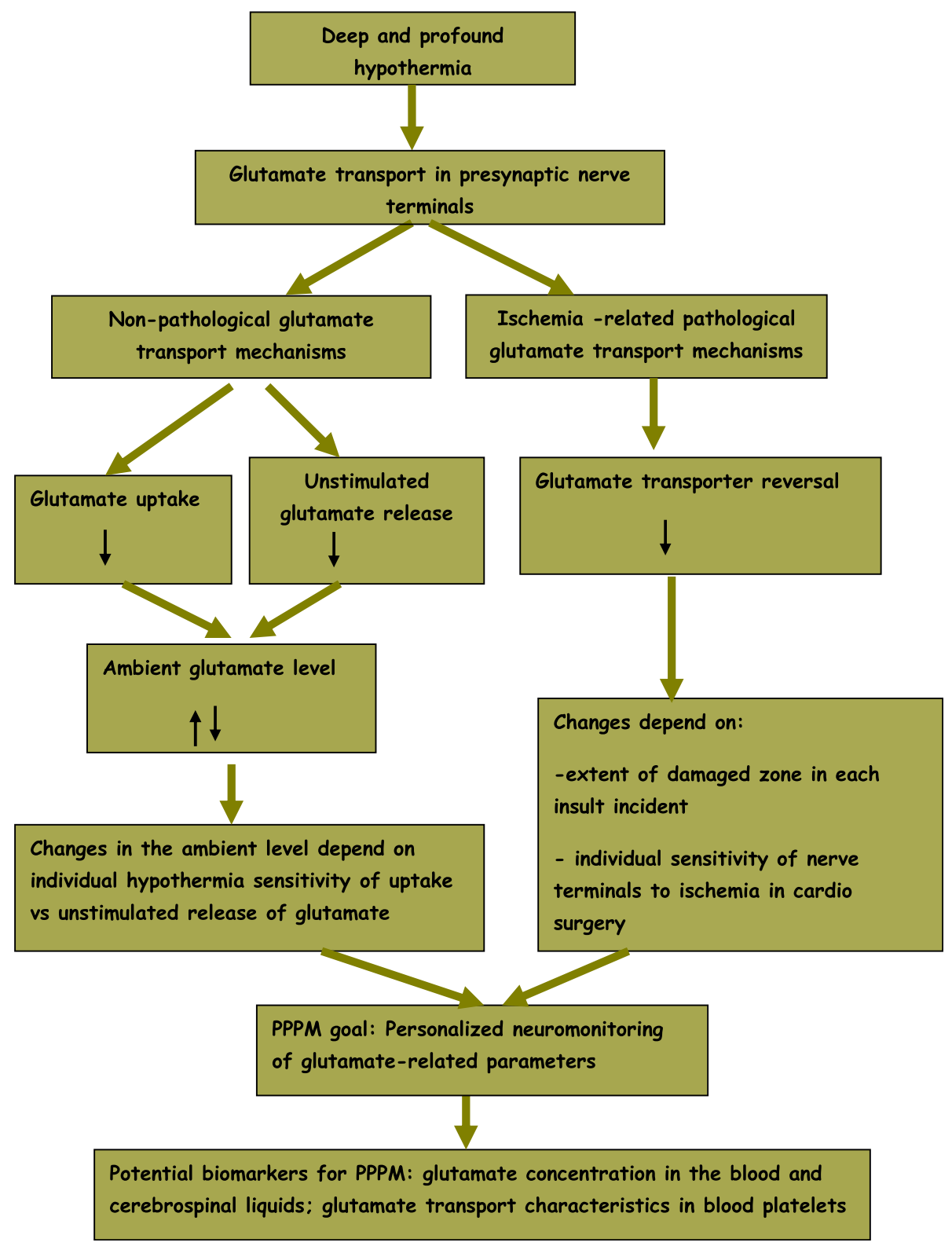

Fig. 8 Roadmap of the study 
transport in blood platelets [35]. These data can be processed in appropriate way and be a base for development of new computational and mathematical tools to predict hypothermia effects.

\section{Conclusions}

Summarizing, dual discrimination of the effects of deep and profound hypothermia on non-pathological and pathological mechanisms of presynaptic glutamate transport was performed using rat brain nerve terminals. Hypothermia-induced changes in extracellular L$\left[{ }^{14} \mathrm{C}\right]$ glutamate in unaffected ischemia nerve terminals are not evident. It is so because the differently directed constituents determined physiological extracellular level, that is, glutamate uptake and tonic release both were decreased in deep and profound hypothermia.

Therefore, in unaffected nerve terminals, the direction of changes in extracellular glutamate in deep and profound hypothermia is unpredictable and depends on individual synaptic characteristics. While in affected ones (e.g., in brain regions suffering from a reduction of blood circulation during cardio surgery and core and penumbra zones of the insult), pathological transportermediated glutamate release decreased with progressive significance from deep to profound hypothermia, thereby underlying its unspecific potent neuroprotective effect in stroke, hypoxia and ischemia, cardiac surgery with application of circulation arrest, and traumatic brain injury, where excitotoxicity progress is associated with an increase in glutamate uptake reversal. Our data revealed the necessity of development and advance of special parameters in PPPM for individual neuromonitoring in hypothermia.

\section{Acknowledgements}

We would like to thank Dr. A. Chunihin for help in dynamic light scattering experiments, M. Dudarenko and K. Paliienko for assistance in the experimental work, and Dr. N. Pozdnyakova for help in database analysis and useful suggestions. This work was supported by Science and Technology Center in Ukraine/National Academy of Sciences of Ukraine project \#6055; Projects of National Academy of Sciences of Ukraine within Programs: "Sensors for medicine, ecology, industry, and technology"; and "Molecular and cellular biotechnology for medicine, industry and agriculture."

\section{Availability of data and materials}

Not applicable

\section{Authors' contributions}

Isolation of synaptosomes and $\mathrm{L}-\left[{ }^{[4} \mathrm{C}\right]$ glutamate release experiments were performed by AP and $\mathrm{L}-\left[{ }^{14} \mathrm{C}\right]$ glutamate uptake experiments by NK. Medical consulting was done by VM. Data analysis and paper writing was done by TB. All authors read and approved the final manuscript.

\section{Competing interests}

The authors declare that they have no competing interests.

\section{Ethics approval and consent to participate}

All procedures were conducted according to the Declaration of Helsinki ("Scientific Requirements and Research Protocols" and "Research Ethics Committees"). Experimental protocols were approved by the Animal Care and Use Committee of the Palladin Institute of Biochemistry (protocol from 19/09-2011).

\section{Author details}

${ }^{1}$ The Department of Neurochemistry, Palladin Institute of Biochemistry, NAS of Ukraine, 9 Leontovicha Str, Kyiv 01601, Ukraine. ${ }^{2}$ Amosov Institute of Cardiovascular Surgery of the Academy of Medical Sciences of Ukraine, $6 \mathrm{~N}$. Amosov Str, Kyiv 03110, Ukraine. ${ }^{3}$ Faculty of Biomedical Engineering, National Technical University of Ukraine "KPI", 16/2 Yangel Str, Kyiv 56, Ukraine.

Received: 28 June 2016 Accepted: 21 October 2016

Published online: 15 December 2016

\section{References}

1. Englum BR, Andersen ND, Husain AM, Mathew JP, Hughes GC. Degree of hypothermia in aortic arch surgery_optimal temperature for cerebral and spinal protection: deep hypothermia remains the gold standard in the absence of randomized data. Ann Cardiothorac Surg. 2013;2:184-93.

2. Attwell D, Laughlin SB. An energy budget for signaling in the grey matter of the brain. J Cereb Blood Flow Metab. 2001;21:1133-45.

3. Kumral E, Yüksel M, Büket S, Yagdi T, Atay Y, Güzelant A. Neurologic complications after deep hypothermic circulatory arrest: types, predictors, and timing. Texas Hear Inst J. 2001;28:83-8.

4. Percy A, Widman S, Rizzo JA, Tranquilli M, Elefteriades JA. Deep hypothermic circulatory arrest in patients with high cognitive needs: full preservation of cognitive abilities. Ann Thorac Surg. 2009;87:117-23.

5. Lakhan SE, Pamplona F. Application of mild therapeutic hypothermia on stroke: a systematic review and meta-analysis. Stroke Res Treat. 2012;2012: 295906.

6. Xing C, Arai K, Lo EH, Hommel M. Pathophysiologic cascades in ischemic stroke. Int J Stroke. 2012;7:378-85.

7. Mrozek S, Vardon F, Geeraerts T. Brain temperature: physiology and pathophysiology after brain injury. Anesthesiol Res Pract. 2012;2012:989487.

8. van der Worp HB, Sena ES, Donnan GA, Howells DW, Macleod MR. Hypothermia in animal models of acute ischaemic stroke: a systematic review and meta-analysis. Brain. 2007;130(Pt 12):3063-74.

9. Kammersgaard LP, Jørgensen HS, Rungby JA, Reith J, Nakayama H, Weber UJ, Houth J, Olsen TS. Admission body temperature predicts long-term mortality after acute stroke: the Copenhagen Stroke Study. Stroke. 2002;33: 1759-62.

10. Berger C, Schäbitz W-R, Georgiadis D, Steiner T, Aschoff A, Schwab S. Effects of hypothermia on excitatory amino acids and metabolism in stroke patients: a microdialysis study. Stroke. 2002;33:519-24.

11. Millán M, Grau L, Castellanos M, Rodríguez-Yáñez M, Arenillas JF, Nombela F, Pérez de la Ossa N, López-Manzanares L, Serena J, Castillo J, Dávalos A. Body temperature and response to thrombolytic therapy in acute ischaemic stroke. Eur J Neurol. 2008;15:1384-9.

12. den Hertog HM, van der Worp HB, van Gemert HMA, Algra A, Kappelle LJ, van Gijn J, Koudstaal PJ, Dippel DWJ. An early rise in body temperature is related to unfavorable outcome after stroke: data from the PAIS study. J Neurol. 2011;258:302-7.

13. Liu L, Yenari MA. Clinical application of therapeutic hypothermia in stroke. Neurol Res. 2009;31:331-5.

14. Danbolt NC. Glutamate uptake. Prog Neurobiol. 2001;65:1-105.

15. Borisova T. Permanent dynamic transporter-mediated turnover of glutamate across the plasma membrane of presynaptic nerve terminals: arguments in favor and against. Rev Neurosci. 2016;27(1):71-81.

16. Grewer C, Gameiro A, Zhang Z, Tao Z, Braams S, Rauen T. Glutamate forward and reverse transport: from molecular mechanism to transportermediated release after ischemia. IUBMB Life. 2008;60:609-19.

17. Rosen AD. Temperature modulation of calcium channel function in $\mathrm{GH} 3$ cells. Am J Physiol. 1996;271(3 Pt 1):C863-8.

18. Volgushev M, Vidyasagar TR, Chistiakova M, Eysel UT. Synaptic transmission in the neocortex during reversible cooling. Neuroscience. 2000;98:9-22.

19. Volgushev M, Kudryashov I, Chistiakova M, Mukovski M, Niesmann J, Eysel UT. Probability of transmitter release at neocortical synapses at different temperatures. J Neurophysiol. 2004;92:212-20. 
20. Rosen AD. Nonlinear temperature modulation of sodium channel kinetics in GH(3) cells. Biochim Biophys Acta. 2001;1511:391-6.

21. Pozdnyakova N, Dudarenko M, Yatsenko L, Himmelreich N, Krupko O, Borisova T. Perinatal hypoxia: different effects of the inhibitors of GABA transporters GAT1 and GAT3 on the initial velocity of [3H]GABA uptake by cortical, hippocampal, and thalamic nerve terminals. Croat Med J. 2014;55: 250-8.

22. McGrath JC, Drummond GB, McLachlan EM, Kilkenny C, Wainwright CL. Guidelines for reporting experiments involving animals: the ARRIVE guidelines. Br J Pharmacol. 2010;160:1573-6.

23. Kilkenny C, Browne W, Cuthill IC, Emerson M, Altman DG. Animal research: reporting in vivo experiments: the ARRIVE guidelines. Br J Pharmacol. 2010; 160:1577-9.

24. Cotman CW. Isolation of synaptosomal and synaptic plasma membrane fractions. Methods Enzymol. 1974;31:445-52.

25. Borisova T, Krisanova N, Himmelreich N. Exposure of animals to artificial gravity conditions leads to the alteration of the glutamate release from rat cerebral hemispheres nerve terminals. Adv Space Res. 2004;33:1362-7.

26. Borisova TA, Himmelreich NH. Centrifuge-induced hypergravity: [3H]GABA and L-[14C]glutamate uptake, exocytosis and efflux mediated by highaffinity, sodium-dependent transporters. Adv Sp Res. 2005:36:1340-5.

27. Borisova TA, Krisanova NV. Presynaptic transporter-mediated release of glutamate evoked by the protonophore FCCP increases under altered gravity conditions. Adv Sp Res. 2008;42:1971-9.

28. Larson E, Howlett B, Jagendorf A. Artificial reductant enhancement of the Lowry method for protein determination. Anal Biochem. 1986;155:243-8.

29. Liu L, Yenari MA. Therapeutic hypothermia: neuroprotective mechanisms. Front Biosci. 2007;12:816-25.

30. Borisova T, Sivko R, Borysov A, Krisanova N. Diverse presynaptic mechanisms underlying methyl- $\beta$-cyclodextrin-mediated changes in glutamate transport. Cell Mol Neurobiol. 2010;30:1013-23.

31. Soldatkin O, Nazarova A, Krisanova N, Borysov A, Kucherenko D, Kucherenko I, Pozdnyakova N, Soldatkin A, Borisova T. Monitoring of the velocity of high-affinity glutamate uptake by isolated brain nerve terminals using amperometric glutamate biosensor. Talanta. 2015;135:67-74.

32. Borisova T. Cholesterol and presynaptic glutamate transport in the brain. New York: Springer; 2013.

33. Jabaudon D, Shimamoto K, Yasuda-Kamatani Y, Scanziani M, Gähwiler BH, Gerber U. Inhibition of uptake unmasks rapid extracellular turnover of glutamate of nonvesicular origin. Proc Natl Acad Sci U S A. 1999;96:8733-8.

34. Sudhof TC. The synaptic vesicle cycle. Annu Rev Neurosci. 2004;27:509-47.

35. Borisova T, Borysov A. Putative duality of presynaptic events. Rev Neurosci. 2016;27(4):377-84

36. Busto R, Globus MY, Dietrich WD, Martinez E, Valdés I, Ginsberg MD. Effect of mild hypothermia on ischemia-induced release of neurotransmitters and free fatty acids in rat brain. Stroke. 1989;20:904-10.

37. Nakashima K, Todd MM. Effects of hypothermia on the rate of excitatory amino acid release after ischemic depolarization. Stroke. 1996;27:913-8.

38. Suehiro E, Fujisawa $H$, Ito H, Ishikawa T, Maekawa T. Brain temperature modifies glutamate neurotoxicity in vivo. J Neurotrauma. 1999;16:285-97.

39. Boris-Möller F, Wieloch T. Changes in the extracellular levels of glutamate and aspartate during ischemia and hypoglycemia. Effects of hypothermia. Exp Brain Res. 1998;121:277-84

40. Nakashima K, Todd MM. Effects of hypothermia, pentobarbital, and isoflurane on postdepolarization amino acid release during complete global cerebral ischemia. Anesthesiology. 1996;85:161-8.

41. Borisova T. The neurotoxic effects of heavy metals: alterations in acidification of synaptic vesicles and glutamate transport in brain nerve terminals. Horizons Neurosci Res. 2014;14:89-112.

42. Borisova T, Borysov A, Pastukhov A, Krisanova N. Dynamic Gradient of Glutamate Across the Membrane: Glutamate/Aspartate-Induced Changes in the Ambient Level of L-[(14)C]glutamate and D-[(3)H]aspartate in Rat Brain Nerve Terminals. Cell Mol Neurobiol. 2016; doi: 10.1007/s10571-015-0321-4

43. Pozdnyakova N, Pastukhov A, Dudarenko M, Galkin M, Borysov A, Borisova T. Neuroactivity of detonation nanodiamonds: dose-dependent changes in transporter-mediated uptake and ambient level of excitatory/inhibitory neurotransmitters. J Nanobiotechnol. 2016;14:25. doi: 10.1186/s12951-016-0176-y.

44. Aliprandi A, Longoni M, Stanzani L, Tremolizzo L, Vaccaro M, Begni B, Galimberti G, Garofolo R, Ferrarese C. Increased plasma glutamate in stroke patients might be linked to altered platelet release and uptake. J Cereb Blood Flow Metab. 2005;25:513-9.
45. do Nascimento C, Nogueira C, Borges V, Rocha J. Changes in $\left[{ }^{3} \mathrm{H}\right]$-glutamate uptake into platelets from patients with bipolar I disorder. Psychiatry Res. 2006;141:343-7.

46. Rainesalo S, Keränen T, Peltola J, Saransaari P. Glutamate uptake in blood platelets from epileptic patients. Neurochem Int. 2003;43:389-92.

47. Zoia C, Cogliati T, Tagliabue E, Cavaletti G, Sala G, Galimberti G, Rivolta I, Rossi $V$, Frattola L, Ferrarese C. Glutamate transporters in platelets: EAAT1 decrease in aging and in Alzheimer's disease. Neurobiol Aging. 2004;25:149-57.

48. Behari M, Shrivastava M. Role of platelets in neurodegenerative diseases: a universal pathophysiology. Int J Neurosci. 2013;123:287-99.

49. Gottlieb M, Wang Y, Teichberg VI. Blood-mediated scavenging of cerebrospinal fluid glutamate. J Neurochem. 2003;87:119-26.

50. Kuo J, Chen S, Huang H, Yang C, Tsai P, Hsueh C. The involvement of glutamate in recall of the conditioned NK cell response. J Neuroimmunol. 2001;118:245-55.

51. O'Kane R, Martínez-López I, DeJoseph M, Viña J, Hawkins R. Na+-dependent glutamate transporters (EAAT1, EAAT2, and EAAT3) of the blood-brain barrier. A mechanism for glutamate removal. J Biol Chem. 1999;274:31891-5.

52. Wang Y, Gottlieb M, Teichberg VI. An evaluation of erythrocytes as plasma glutamate scavengers for enhanced brain-to-blood glutamate efflux. Neurochem Res. 2004;29:755-60.

53. Savcheniuk O, Virchenko O, Falalyeyeva T, Beregova T, Babenko L, Lazarenko $L$, Demchenko O, Bubnov R, Spivak M. The efficacy of probiotics for monosodium glutamate-induced obesity: dietology concerns and opportunities for prevention. EPMA J. 2014;5(1):2. doi:10.1186/1878-5085-5-2.

\section{Submit your next manuscript to BioMed Central and we will help you at every step:}

- We accept pre-submission inquiries

- Our selector tool helps you to find the most relevant journal

- We provide round the clock customer support

- Convenient online submission

- Thorough peer review

- Inclusion in PubMed and all major indexing services

- Maximum visibility for your research

Submit your manuscript at www.biomedcentral.com/submit
( Biomed Central 